\title{
Accuracy Analysis of Structure Modeling using Continuous Panoramic Image
}

\author{
Joon-Kyu Park ${ }^{1)}$ and Dae-Yong $\mathrm{Um}^{2)}$ \\ 1) 131-702 Dept. of Civil Engineering, Seoil University, 28, Yongmasan-ro 90-gil, \\ Jungnang-gu, Seoul, Korea \\ 2) (Corresponding Author) 380-702 Dept. of Civil Engineering, Korea National \\ University of Transportation, 50, Daehak-ro, Chungju-si, Chungbuk, Korea \\ jkpark@seoil.ac.kr,dyum@ut.ac.kr
}

\begin{abstract}
In this study, a 3D model was constructed using Continuous Panoramic Image and accuracy analysis of $3 D$ modeling data was performed. The way for $3 D$ modeling using images and SketchUp greatly reduced the time and the coordinates of the target object were effectively collected in panoramic images. Accuracy analysis of the modeling result was performed by comparing coordinates with the total station. As a result of the accuracy evaluation of the $3 D$ model, the horizontal and vertical deviations were $0.06 \mathrm{~m}$ and $0.128 \mathrm{~m}$, respectively. Our results suggest that it is possible to reduce the operation time by 30\% compared to modeling using existing laser scanner; also, panorama images can be used in various content businesses. The proposed method of 3D modeling reported in this study greatly reduces effort and time and can contribute to $3 D$ modeling and other relevant areas.
\end{abstract}

Keywords: 3D Modeling, Panoramic Image, GNSS, Accuracy Analysis

\section{Introduction}

Spatial information is not merely delivering the location information; rather, it is gradually becoming a part of our life. In recent years, it has also developed into a technique changing our life-style [1-5]. In many advanced countries, 3D spatial information is used in major national projects, and those countries are striving for dominating the market in advance. In the United States, the distribution of spatial information is very active in private studies and in creating business models. "Spatial data industry future vision" policy has been recently published in Japan and it is being fully employed as a crisis management system in the disaster and prevention fields. In China, the "Digital City Geospatial Platform Construction" project was launched in 2010; until 2015, the plan is to construct high accuracy 3D spatial data of 286 cities in China [6][7]. Recently, 3D modeling data have been variously utilized in many fields, as, for example, GIS (Geographic Information System) analysis, 3D Content industry, and so on. Among global 3D content industries, the 3D display market is expected to grow by $40 \%$ annually. One of the estimates predicts that the 3D content market in Korea will increase by $90 \%$ each year, creating a market of 2.5 trillion won by 2015 [8] [10]. 3D models represent a 3D object using a collection of geospatial information in 3D space, connected by various geometric entities, such as triangles, lines, curved surfaces, among others. Being a collection of data, such as points with 3D coordinates, 3D models can be created manually, algorithmically, or be scanned [11-12].

3D modeling of spatial information has a characteristic for observing the entire image area by moving a point of sight or rotating 3D models. In order to construct 3D models, data source, equipment(S/W \& H/W), modeling method, and visualization technique are generally needed. In the spatial information construction fields, various techniques of 
getting spatial data, such digital aerial photogrammetry, high-resolution satellite image data, unmanned aerial vehicle, MMS (Mobile Mapping System), and others are now being developed[13-16]. However, 3D model construction is a high-cost and labor-intensive work. In this context, it becomes crucial to develop ways to efficiently construct highprecision geometric structure.

In this study, a 3D model of Dongnimmun Gate was made by digital photogrammetry system using V10 Imaging Rover. Panoramic images of the research area were acquired, from which the coordinates of the target object were collected. Accuracy analysis of the modeling results was performed by comparing with the total station. Figure 1 shows the study flow diagram.

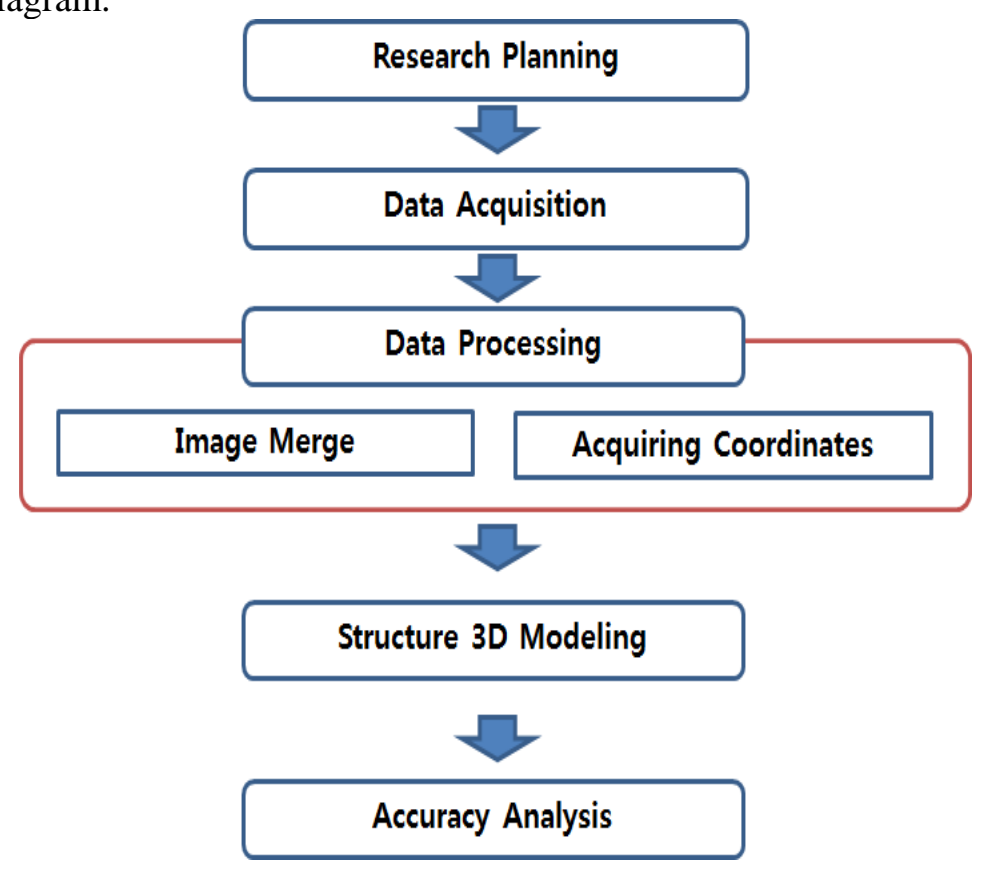

Figure 1. Study Flow

\section{Data Acquisition and Processing}

In this study, Dongnimmun Gate was selected as the target object furthermore, the data for 3D modeling were acquired. Dongnimmun Gate was constructed under an independent association which was organized by Seo Jae-pil, and the construction was greatly supported by many patriots. It was modeled on the Arc de Triomphe in Paris. Figure 2 shows Dongnimmun Gate.

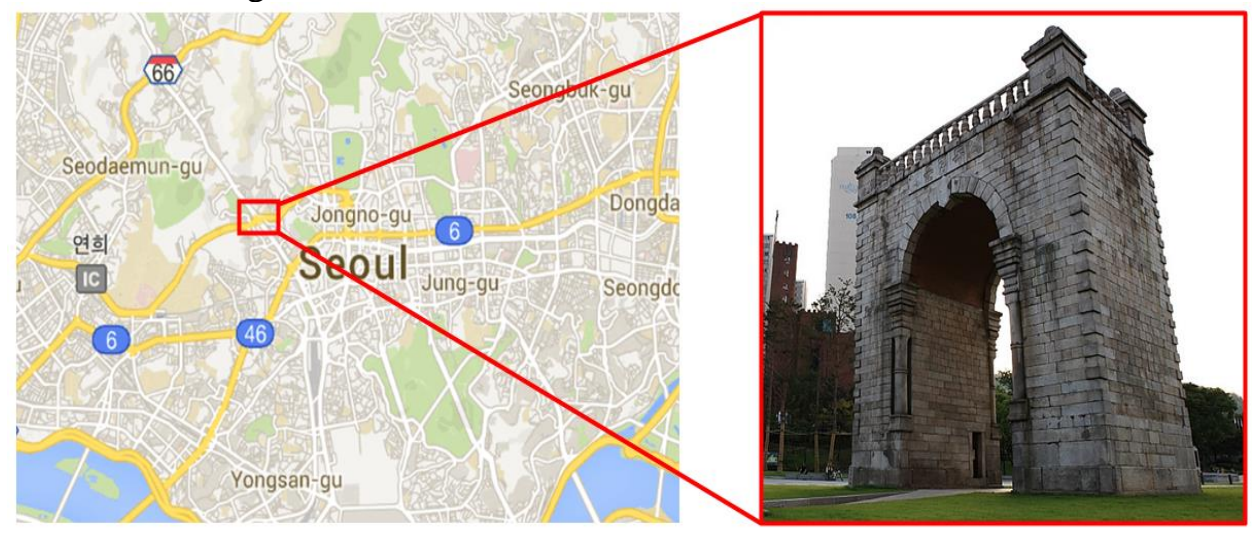

Figure 2. Dongnimmun Gate 
Trimble V10 Imaging Rover was used to acquire a panoramic image for 3D modeling. V10 can get a 60 million pixel panoramic image using 12 cameras that conduct calibration work; it consists of a controller and the main body mounted on the position sensor, tilt sensor, and electronic compasses. There are two methods to get a panorama image for digital photogrammetry. The first one is to connect GNSS and the total station; the second one is to measure the target object from the station point. In this study, the first method was used for getting the panorama image. Table 1 shows specification of V10; Figure 3 demonstrates the configuration of the V10 Imaging Rover [17].

Table 1. Specification of V10

\begin{tabular}{|c|c|}
\hline Specification & Value \\
\hline Total Panorama Resolution & $60 \mathrm{MP}$ \\
\hline FOV(Horizontal) & $360^{\circ} \times 43^{\circ}, 210^{\circ} \times 57.5^{\circ}$ \\
\hline FOV(Vertical) & $93.1^{\circ}$ \\
\hline Operation Temperature & $-20^{\circ} \mathrm{C}$ to $+50^{\circ} \mathrm{C}$ \\
\hline 2 axis tilt sensor range & $15^{\circ}$ \\
\hline Tilt sensor accuracy & $0.03^{\circ}$ \\
\hline Magnetic sensor accuracy & $1^{\circ}$ \\
\hline Operation Time & 4 hours \\
\hline Lens type & $\mathrm{f}$-theta \\
\hline Angle per pixel & $0.39 \mathrm{mrad} /$ Pix $(1.33 \mathrm{arcmin} / \mathrm{Pix})$ \\
\hline Focal length & $3.63 \mathrm{~mm}$ \\
\hline Depth of field & 0.1 to $\infty \mathrm{m}$ \\
\hline Stability of calibration & $2 \mathrm{Pix}$ \\
\hline
\end{tabular}

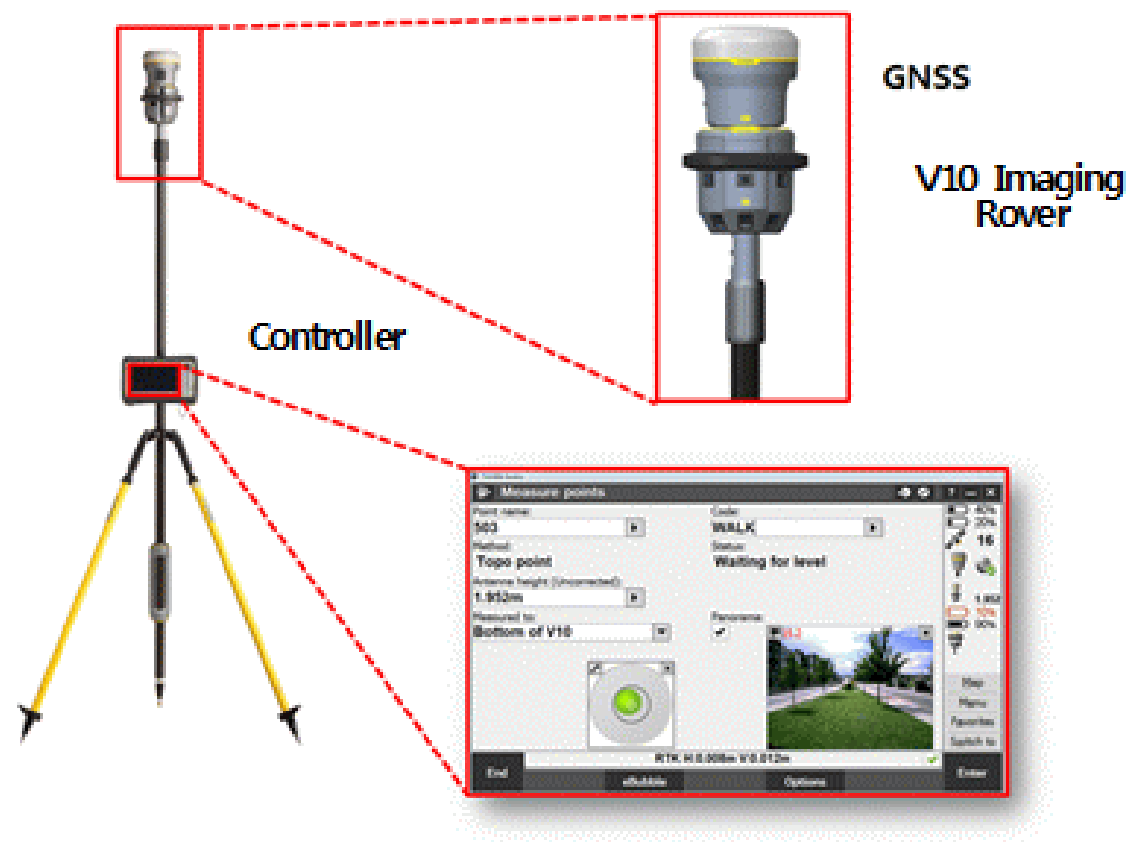

Figure 3. Configuration of the V10 Imaging Rover 
The sequence of 3D modeling using V10 Imaging Rover includes taking a picture of the target object, image data post processing, and 3D modeling. Taking a picture $45 \mathrm{~m}$ away from the target object was conducted 9 times and, after the image data postprocessing using TBC (Trimble Bussiness Center), a 3D model was constructed by SketchUp. Figure 4 shows the work flow of 3D Modeling.

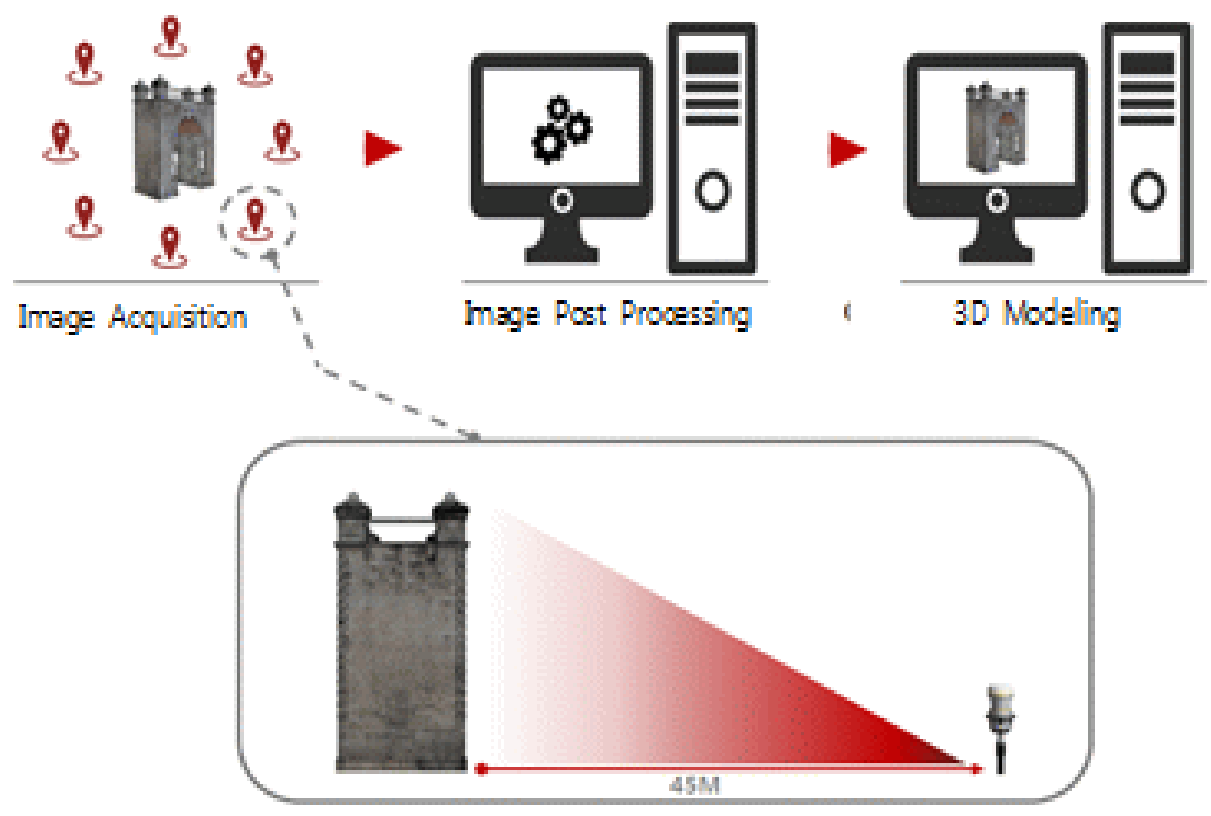

Figure 4. Work Flow of 3D Modeling

In the image, 9 coordinates were acquired using VRS (Virtual Reference Station); furthermore, 13 check points were directly measured for accuracy evaluation. 12 pictures, including acquired points from the image, were automatically created as panoramic image through TBC; then, coordinate acquisition from the video was conducted by adjusting type point. Figure 5 shows the data acquisition screen; Figure 6 represents the status of measuring point.

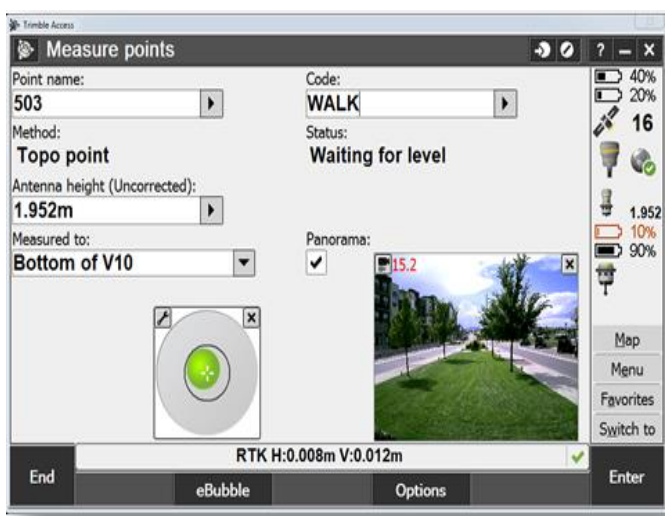

Figure 5. Data Acquisition Screen

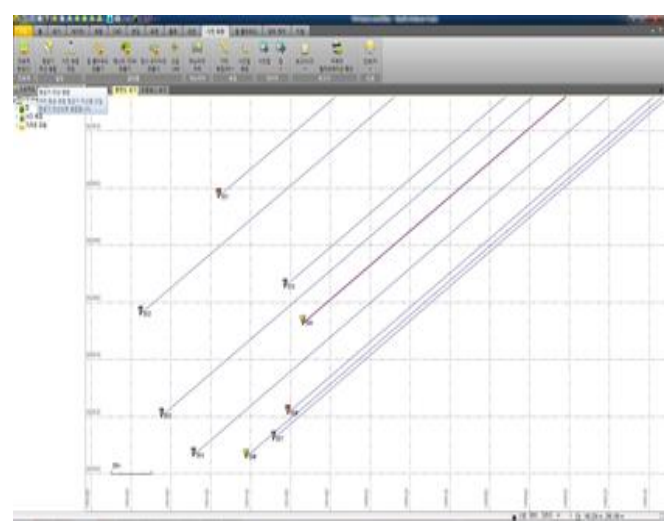

Figure 6. Status of Measuring Point 
Type point adjustment is generally conducted manually or automatically and the points of contact are extracted between the acquired panorama images and then adjusted. In this study, automatic adjustment was conducted through standard resection and more than 12 points in each image were extracted. After adjusting the type point, it was measured for 3D modeling. Figure 7 shows the result of Tie Point Adjustment; Figure 8 presents surveying using the panoramic image.

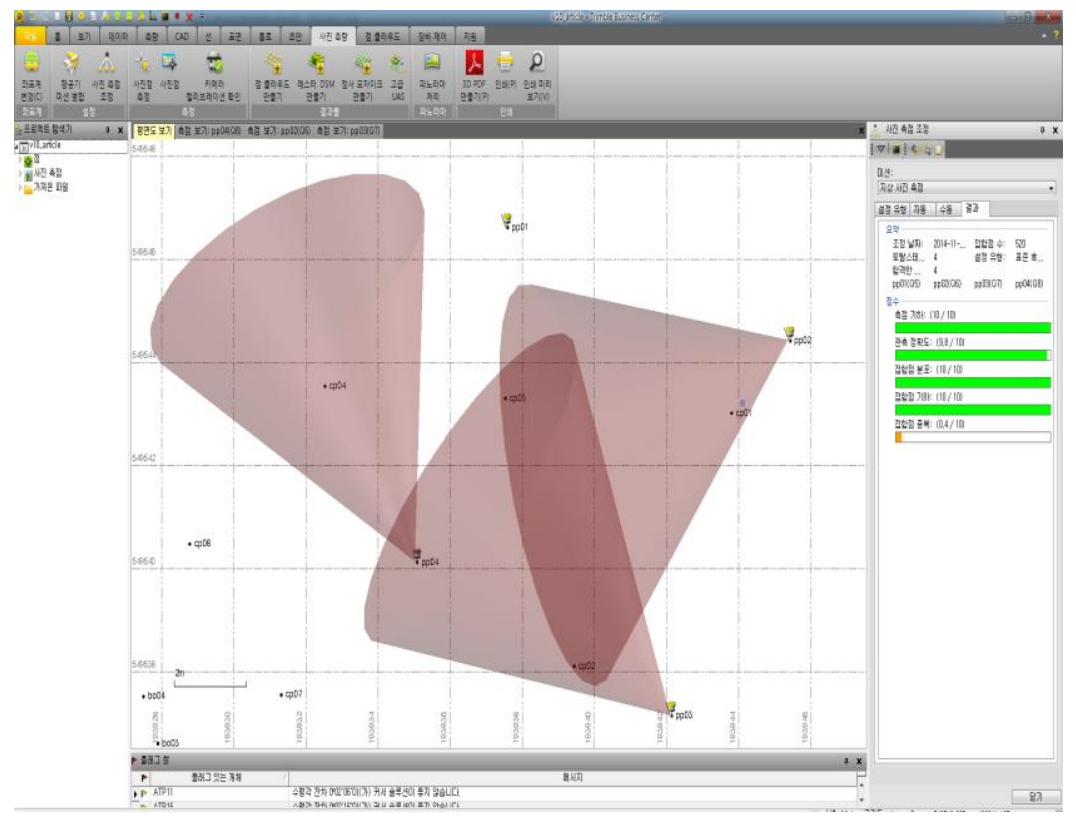

Figure 7. Result of Tie Point Adjustment

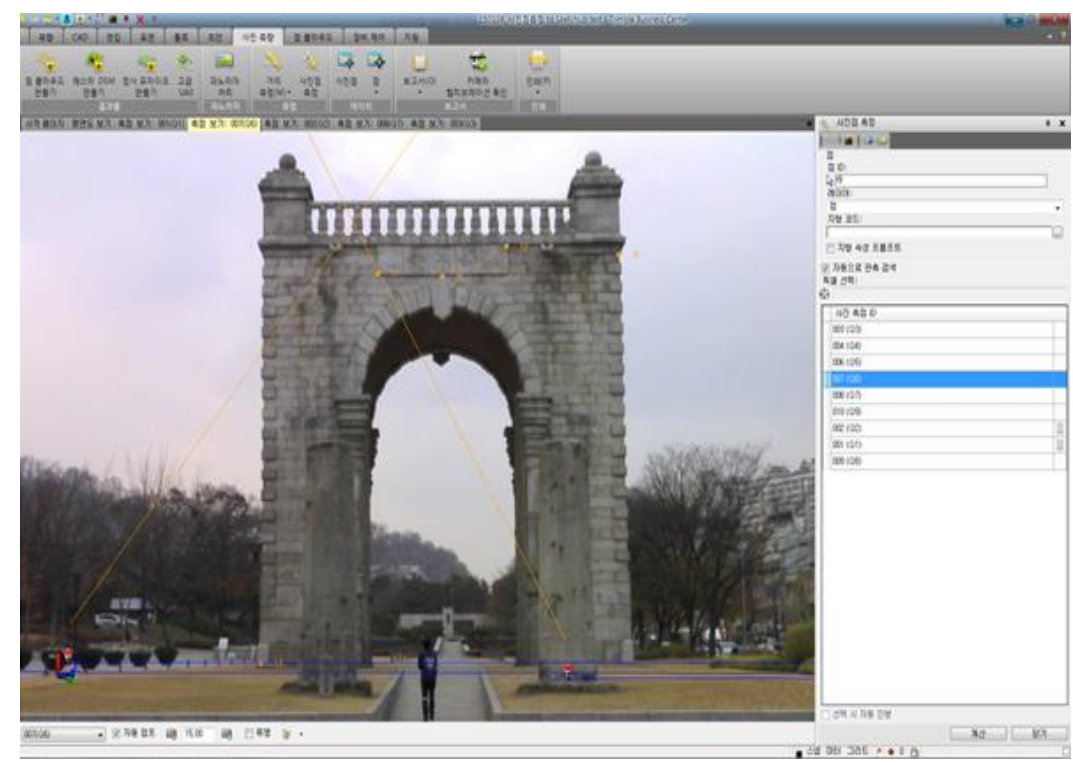

Figure 8. Surveying Using Panoramic Image

3D modeling of Dongnimmun Gate was carried out in SketchUp by using the extracted type point from TBC. The sequence of SketchUp modeling included the creation of an 
image igloo, 3D modeling, texture mapping, and linkage with Google Earth. Figures 9-12 present the process of SketchUp modeling.

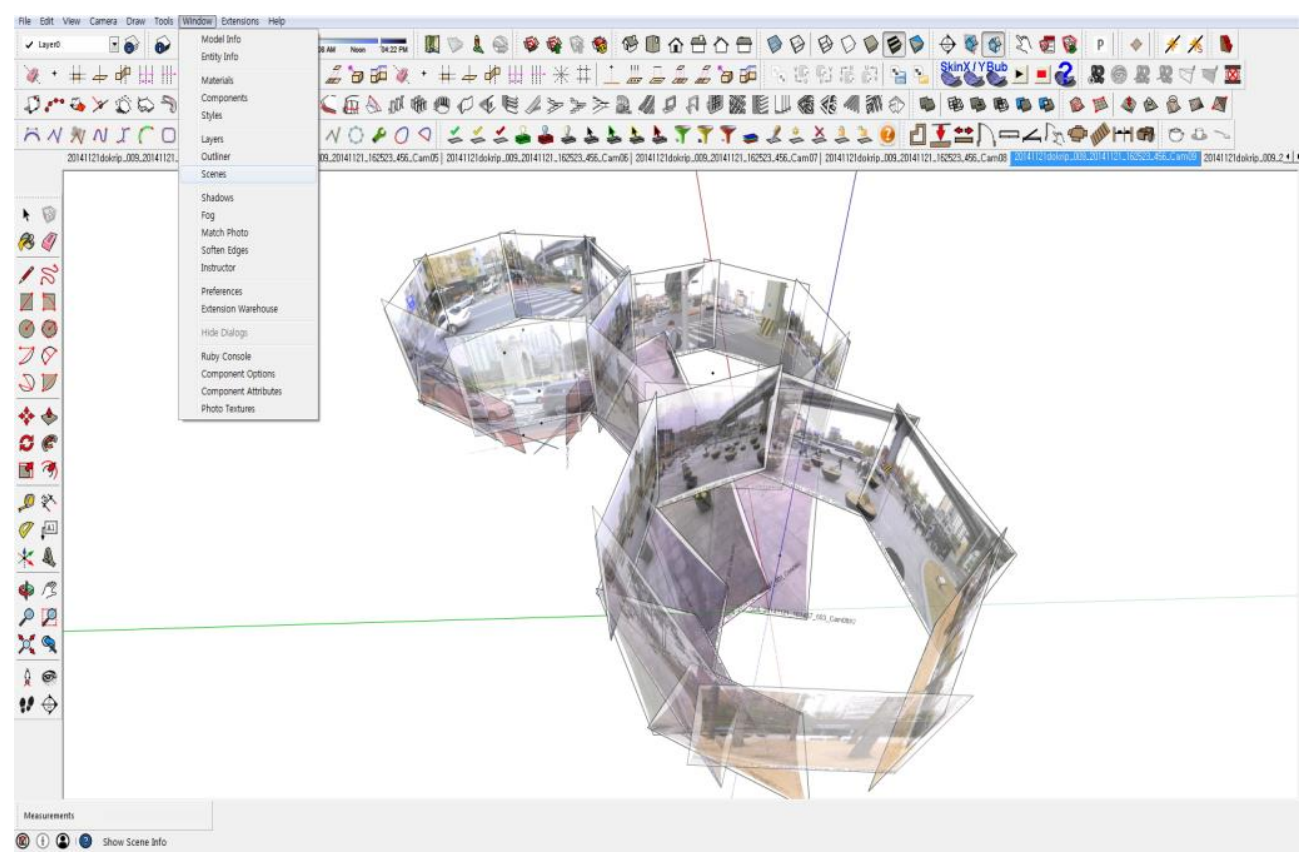

Figure 9. Image Igloo

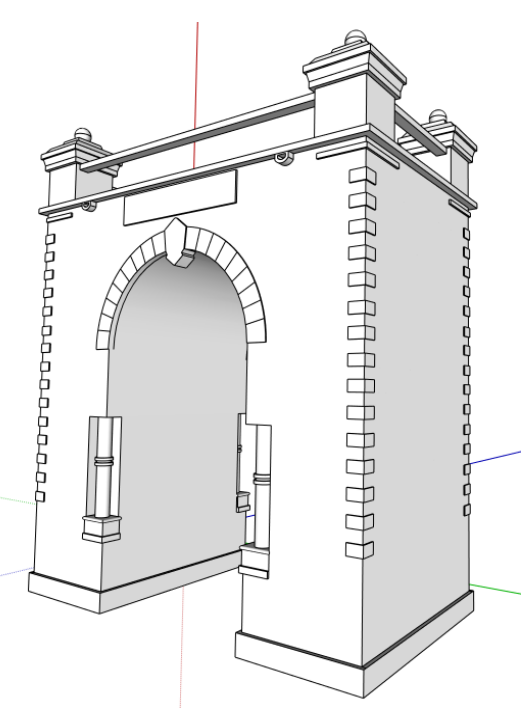

Figure 10. 3D Modeling

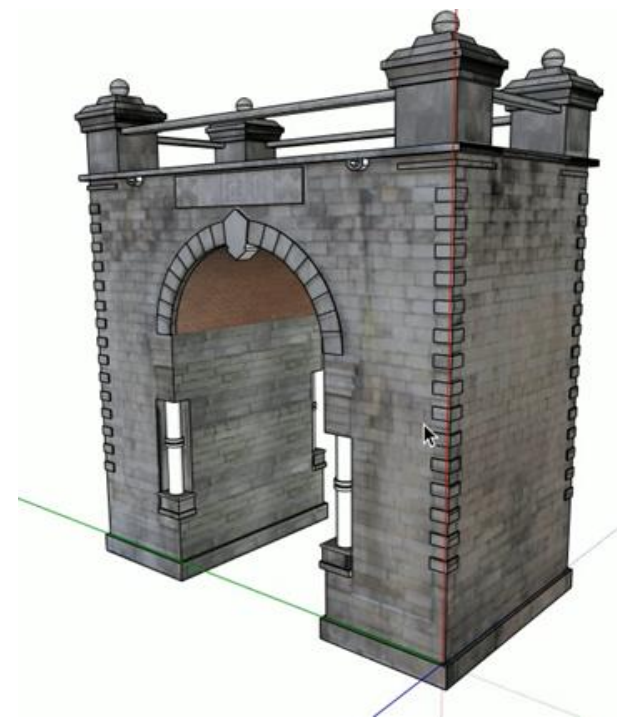

Figure 11. Texture Mapping 


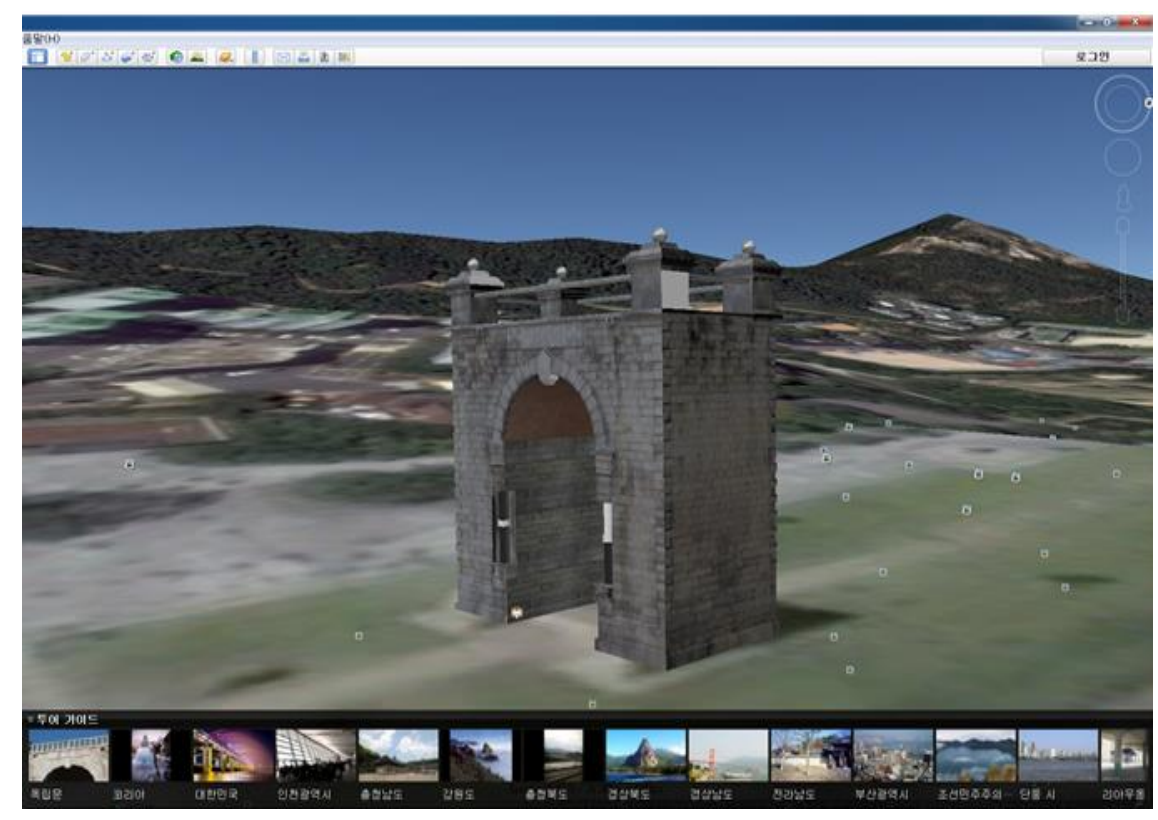

Fig. 12. Link Result with Google Earth

3D modeling of Dongnimmun Gate using V10 Imaging Rover and SketchUp took 6 hours from taking a picture of the target object to the 3D modeling data construction. Therefore, compared to modeling using existing laser scanners, the operation time was reduced by $30 \%$. Panorama images can also be used in various content businesses.

Furthermore, accuracy analysis of the modeling result was performed by comparing with the total station. For accuracy evaluation, a total of 15 points which were clearly detected from the panoramic image were selected as check points and the coordinates of N, E, H directions were compared. Figure 13 shows the check points; Fig. 14 is the deviation graph.

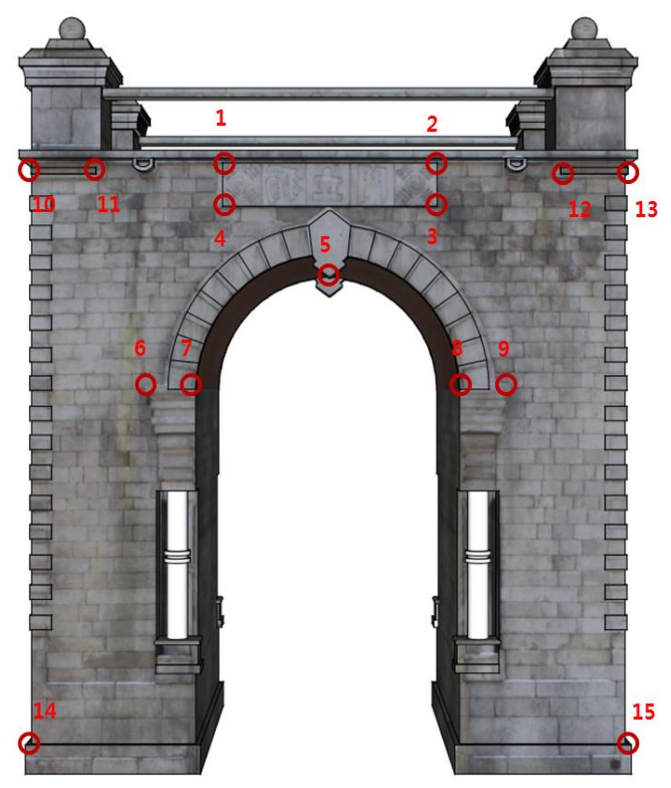

Figure 13. Check Points 


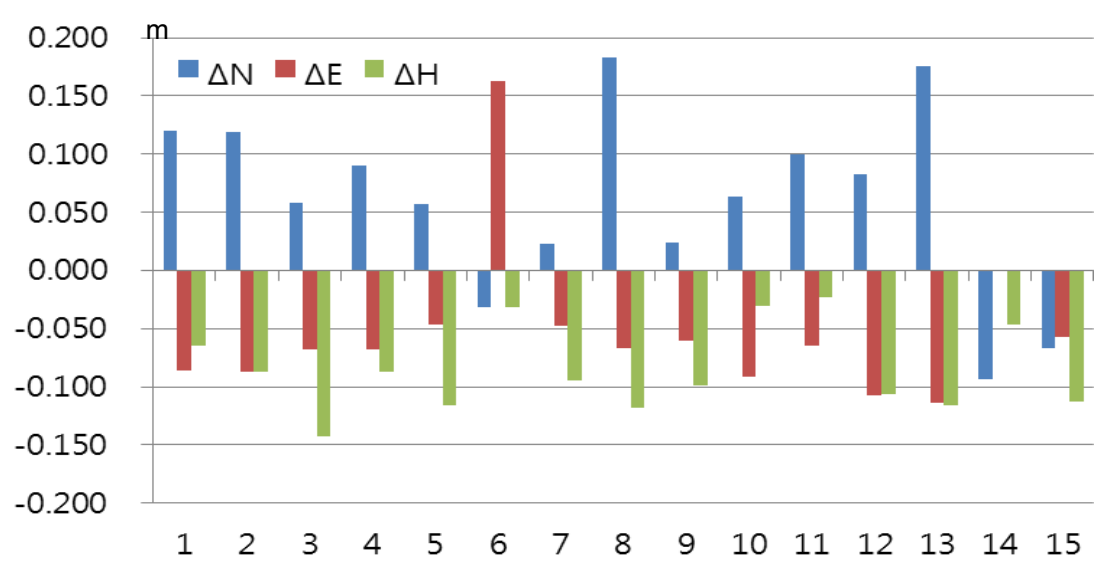

Figure 14. Deviation Graph

Table 2. Results of Accuracy Evaluation

\begin{tabular}{|c|c|c|c|c|c|c|c|c|c|}
\hline No. & Northing & Easting & Height & Northing & Easting & Height & $\Delta \mathrm{N}$ & $\Delta \mathrm{E}$ & $\Delta \mathrm{H}$ \\
\hline 1 & 552539.565 & 196426.247 & 58.598 & 552539.445 & 196426.333 & 58.663 & 0.120 & -0.086 & -0.065 \\
\hline 2 & 552542.219 & 196429.461 & 58.538 & 552542.100 & 196429.548 & 58.625 & 0.119 & -0.087 & -0.087 \\
\hline 3 & 552542.210 & 196429.452 & 57.760 & 552542.152 & 196429.520 & 57.903 & 0.058 & -0.068 & -0.143 \\
\hline 4 & 552539.564 & 196426.255 & 57.788 & 552539.474 & 196426.323 & 57.875 & 0.090 & -0.068 & -0.087 \\
\hline 5 & 552540.885 & 196427.860 & 56.493 & 552540.828 & 196427.907 & 56.609 & 0.057 & -0.047 & -0.116 \\
\hline 6 & 552538.644 & 196425.394 & 54.092 & 552538.675 & 196425.231 & 54.124 & -0.031 & 0.163 & -0.032 \\
\hline 7 & 552539.226 & 196426.217 & 54.376 & 552539.203 & 196426.265 & 54.47 & 0.023 & -0.048 & -0.094 \\
\hline 8 & 552542.288 & 196429.795 & 54.093 & 552542.105 & 196429.862 & 54.211 & 0.183 & -0.067 & -0.118 \\
\hline 9 & 552542.852 & 196430.613 & 54.363 & 552542.828 & 196430.673 & 54.462 & 0.024 & -0.060 & -0.099 \\
\hline 10 & 552536.993 & 196423.376 & 58.646 & 552536.929 & 196423.467 & 58.676 & 0.064 & -0.091 & -0.030 \\
\hline 11 & 552538.058 & 196424.665 & 58.635 & 552537.958 & 196424.730 & 58.658 & 0.100 & -0.065 & -0.023 \\
\hline 12 & 552543.479 & 196431.191 & 58.608 & 552543.396 & 196431.298 & 58.714 & 0.083 & -0.107 & -0.106 \\
\hline 13 & 552544.535 & 196432.470 & 58.598 & 552544.359 & 196432.584 & 58.714 & 0.176 & -0.114 & -0.116 \\
\hline 14 & 552537.228 & 196423.371 & 47.726 & 552537.321 & 196423.372 & 47.772 & -0.093 & -0.001 & -0.046 \\
\hline 15 & 552544.387 & 196432.025 & 47.753 & 552544.454 & 196432.082 & 47.866 & -0.067 & -0.057 & -0.113 \\
\hline & & Avandard Deviation & & 0.060 & -0.054 & -0.128 \\
\hline & & & & & 0.080 & 0.066 & 0.115 \\
\hline
\end{tabular}


As a result of accuracy evaluation, the deviation of horizontal (Northing, Easting) direction was $-0.114 \mathrm{~m} \sim 0.183 \mathrm{~m}$ and the average of deviation was ca. $0.06 \mathrm{~m}$. The deviation of vertical direction was $-0.024 \mathrm{~m} \sim-0.170 \mathrm{~m}$ and the average was around $0.128 \mathrm{~m}$.

These results suggest that 3D modeling using V10 Imaging Rover and SketchUp can be fully employed in modeling work. The method used in this study can reduce the time for actual survey and 3D modeling compared to existing laser scanner, the total station, or GNSS. Furthermore, acquired images can be variously used in texture mapping. Continuous panoramic images will contribute to 3D modeling and various content industries.

\section{Conclusion}

In this study, 3D modeling using V10 Imaging Rover and SketchUp was conducted, followed by the evaluation of accuracy of the modeling data. Our results suggest the following conclusions.

First, 3D modeling of Dongnimmun Gate was efficiently conducted by the procedure of taking a picture of the target object, image data post-processing, and 3D modeling using the acquired coordinates by panoramic image and SketchUp.

Second, compared to the existing laser scanner, total station, or GNSS, the method of using continuous panoramic image could reduce the time for actual survey and 3D modeling; the acquired images can be used in texture mapping.

Third, the specific values of deviation obtained in horizontal and vertical direction let us conclude that the result using continuous panoramic images can be fully used in 3D modeling work.

Fourth, the results of the present study contribute to the promotion of the $3 \mathrm{D}$ content industry and technical capabilities.

\section{References}

[1] J.-K. Park, J.-S. Lee and H.-C. Yun, "Efficient Construction of 3D Modeling Data using Panoramic Scene", Advanced Science and Technology Letters, (2015), vol. 89, pp.156-159.

[2] J.-K. Park and M.-G. Kim, "Construction of Ortho Image for Efficient Forest Management Using UAS", Contemporary Engineering Sciences, (2014), vol.7, no.24, pp. 1389 - 1395.

[3] S.-H. Han and J.-S. Lee, "Availability Evaluation of Topographic Surveying Using Panoramic Image", Asia-Pacific Journal of Multimedia Services Convergent with Art, Humanities, and Sociology, (2014), vol.4, no.2, pp. 347-358.

[4] M.-G. Kim, G.-Y. Jung, J.-B. Kim, H.-C. Yun, “Applicability Analysis of UAV for Storm and Flood Monitoring" Journal of the Korean Society of Surveying, Geodesy, Photogrammetry and Cartography, (2010), vol.28, no.8, pp.655-662.

[5] J.-H. Lee, K.-A. Choi and I.-P. Lee, "Calibration of a UAV Based Low Altitude Multi-sensor Photogrammetric System”, Journal of Korean Society for Geospatial Information System, (2012), vol.30, no.1, pp.31-38.

[6] S.-H. Jung, H.-M. Lim and J.-K. Lee, "Acquisition of 3D Spatial Information using UAV Photogrammetric Method", Journal of the Korean Society of Surveying, Geodesy, Photogrammetry and Cartography, (2010), vol.28, no.1, pp.161-167.

[7] B. Cui, C. Wang and Q. Wang, "Remote Sensing Images Data Integration Based on the Agent Service", International Journal of Grid and Distributed Computing , (2008), vol.1, no.1, pp.23-30.

[8 V.-T. Minh and A.-M. Abdul Rani, "The Review on Computer Modeling and Computer Experiment in Pedagogical Researches in the Example of Uzbek Education System", International Journal of Advanced Science and Technology, (2009), vol. 11, pp. 41-48.

[9] S.-Y. Hwang and D.-H- Yu, "GPS Localization Improvement of Smartphones Using Built-in Sensors", International Journal of Smart Home, (2012), vol.6, no3, pp.1-8.

[10] R. Hashim, M.-S. Ikhmatiar, M.-S. Masiri Karmin, T. Herawan, "Mosque Tracking on Mobile GPS and Prayer Times Synchronization for Unfamiliar Area", International Journal of Future Generation Communication and Networking, (2011), vol.4, no.2, pp.37-48.

[11] A.-M. Hasan, K. Samsudin and A.-R. Ramli, "GPS/INS Integration Based on Dynamic ANFIS Network", International Journal of Control and Automation, (2012), vol.5, no.3, pp.1-22. 
[12] D.-C. Lee and J.-H. Yom, "Generation of Building and Contour Layers for Digital Mapping Using LiDAR Data", Journal of the Korean Society of Surveying, Geodesy, Photogrammetry and Cartography, (2005), vol.23, no.3, pp.313-322.

[13] H.-C. Yun, M.-G. Kim and J.-S. Lee, "Management of Road Pavement by Mobile Mapping System", Advanced Science and Technology Letters, (2014), vol.62, pp. 61-65.

[14] S. Lee and K. Chung, "The Study of Dynamic Video Frame Mapping Scheme for Multimedia Streaming over IEEE 802.11e WLAN", International Journal of Multimedia and Ubiquitous Engineering, (2013), vol. 8, no. 1, pp. 163-174.

[15] A.K. Helmy and G.H.S.El-Taweel, "Authentication Scheme Based on Principal Component Analysis for Satellite Images", International Journal of Signal Processing, Image Processing and Pattern Recognition, (2009), vol.2, no.3, pp.1-10.

[16] N. Patel and M. Zaveri, "3D Facial Model Construction and Expressions Synthesis using a Single Frontal Face Image”, International Journal of Computer Graphics, (2010), vol. 1, no.1, pp.1-18.

[17] www.trimble.com
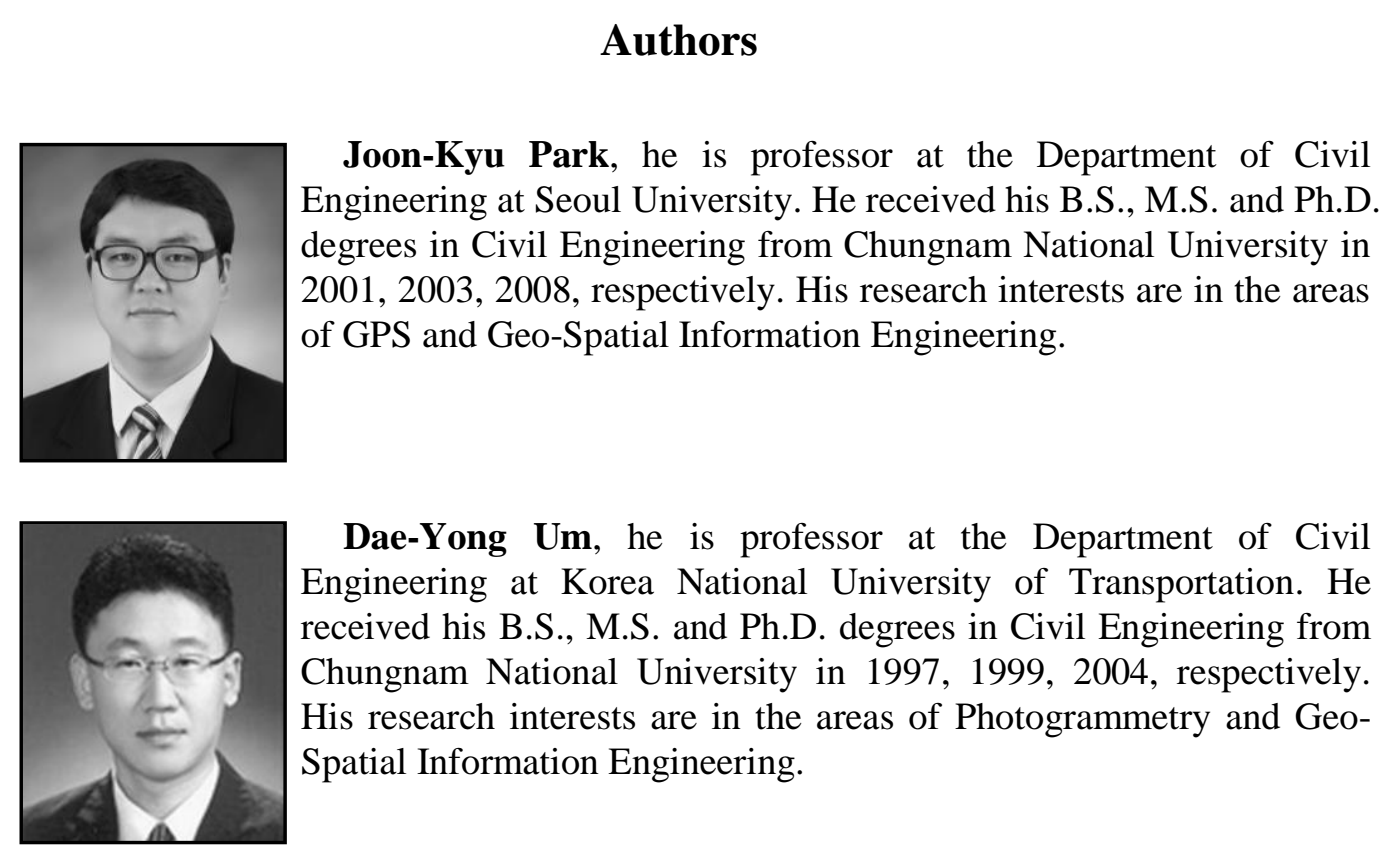

Dae-Yong Um, he is professor at the Department of Civil Engineering at Korea National University of Transportation. He received his B.S., M.S. and Ph.D. degrees in Civil Engineering from Chungnam National University in 1997, 1999, 2004, respectively. His research interests are in the areas of Photogrammetry and GeoSpatial Information Engineering. 